\title{
GA-A20624 \\ OCt $0>1991$ \\ A SYSTEM TO DEPOSIT BORON FILMS (BORONIZATION) \\ IN THE DIII-D TOKAMAK
}

\author{
by \\ T.R. HODAPP, G.L. JACKSON, J. PHILLIPS, \\ K.L. HOLTROP, P.I. PETERSEN, and J. WINTER
}

SEPTEMBER 1991

\section{GENERAL ATOMICS}




\section{DISCLAIMER}

This report was prepared as an account of work sponsored by an agency of the United States Government. Neither the United States Government nor any agency thereof, nor any of their employees, makes any warranty, express or implied, or assumes any legal liability or responsibility for the accuracy, completeness, or usefulness of any information, apparatus, product, or process disclosed, or represents that its use would not infringe privately owned rights. Reference herein to any specific commercial product, process, or service by trade name, trademark, manufacturer, or otherwise, does not necessarily constitute or imply its endorsement, recommendation, or favoring by the United States Government or any agercy thereof. The views and opinions of authors expressed herein do not necessarily state or reflect those of the United States Government or any agency thereof. 


\title{
A SYSTEM TO DEPOSIT BORON FILMS (BORONIZATION) IN THE DIII-D TOKAMAK
}

\author{
by \\ T.R. HODAPP, G.L. JACKSON, J. PHILLIPS, \\ K.L. HOLTROP, P.I. PETERSEN, and J. WINTER*
}

This is a preprint of a paper to be presented at the 14th IEEE Symposium on Fusion Engineering, September 30-October 3, 1991, San Diego, California, and to be printed in the Proceedings.

\author{
Work supported by \\ U.S. Department of Energy \\ Contract DE-AC03-89ER51114
}

*Institut für Plasmaphysik, Forschungszentrum Jülich $\mathrm{GmbH}$, Association EURATOM-FKA, Jülich, F.R.G.

GENERAL ATOMICS PROJECT 3466 SEPTEMBER 1991

\section{GEMERAL ATOMIES




\title{
A SYSTEM TO DEPOSIT BORON FILMS (BORONIZATION) IN THE DIII-D TOKAMAK
}

\author{
T.R. Hodapp, G.L. Jackson, J. Phillips, K.L. Holtrop, and P.I. Petersen \\ General Atomics \\ P.O. Box 85608, San Diego, California 92186-9784
}

\section{J. Winter}

Institut fur Plasmaphysik, Forschungseentrum Jülich GmbH Association EURATOM-FKA, P.O. Box 1913, Jülich, F.R.G.

\begin{abstract}
A system has been added to the DIII-D tokamak to coat its plasma facing surfaces with a film of boron using diborane gas. The system includes special health and safety equipment for handling the diborane gas which is toxic and inflammable. The purpose of the boron film is to reduce the levels of impurity atoms in the DIII-D plasmas. Experiments following the application of the boron film in DIII-D have led to significant reductions in plasma impurity levels and the observation of a new, very high confinement regime.
\end{abstract}

\section{Introduction}

A pure plasma containing no impurities is ideal for achieving a self-sustained fusion reaction. Impurities can suppress plasma performance in at least two ways: radiation and dilution. Impurities radiate power from both the hot planma core and plasma edge thereby cooling the plasma and raising the power input requirements for plaoma heating. Impurities also dilute the plasma lowering the fusion power output density. Because impurities play a deleterious role, there is great motivation to develop ways to reduce their levels in fusion plasmas.

Carbon, oxygen and metals (mainly nickel) are the dominant impurities in DIII-D plasmas. The source of carbon is the graphite used on $40 \%$ of the plasma facing surfaces and the source of nickel is the Inconel 625 vacuum vessel. The sources of oxygen are many, for example air leaks, water vapor trapped in the graphite, metal oxides, and volatile $\mathrm{CO}$. Boronization is capable of simultaneously reducing carbon, oxygen, and metals. The boronization process [1] uses diborane gas to deposit a boron film on the plasma facing surfaces by plasma enhanced chemical vapor deposition (PECVD). The main advantage of boronization over other techniques such as helium glow wall cleaning (HeGWC) and carbonization is that boronization reduces oxygen to very low levels and this reduction continues for many days of plasma experiments.

The beneficial effects of boronization are essentially due to the following three factors [2]:

1. The boron atoms in the film capture (i.e., getter) oxygen atoms from the plasma forming $\mathrm{B}_{2} \mathrm{O}_{3}$ which is stable and nonvolatile [3]. This is in contrast to carbon surfaces on which volatile $\mathrm{CO}$ is formed; chemical sputtering later returns the original oxygen impurity atom and an additional carbon impurity atom to the discharge.

2. Boronization films only contain atoms with low mass number (B, C, D). These films cover other impurities (e.g., metals) that might otherwise be desorbed by fast proton bombardment (i.e., sputtered).

3. Boronization films provide a stronger bond for carbon atoms than does a pure carbon film. This reduces chemical erosion (factor up to 10) by deuterium atoms and sputtering ions.

\section{Background - Boronization and Diborane}

Boronization was first developed and used in the TEXTOR tokamak at KFA Jülich (1988) [4] and has since been used on several other tolamaks such as ASDEX, TCA, and TFTR [5]. It is the same process as carbonization (i.e., PECVD) except boronization uses diborane $\left(\mathrm{B}_{2} \mathrm{H}_{6}\right)$ diluted in about $90 \%$ helium and carbonization uses methane $\left(\mathrm{CH}_{4}\right)$. Deuterated gases $\left(\mathrm{B}_{2} \mathrm{D}_{6}\right.$, $C D_{4}$ ) are used in DIII-D to maximize the isotopic ratio D/H during subsequent plasma experiments. Boronization deposits an amorphous boron-rich film, typically $100 \mathrm{~nm}$ (400 monolayers) thick, which contains about $40 \%$ deuterium [6].

A film made of B, C, and D can be deposited using a mixture of diborane in belium and methane. The $B / C$ ratio of the film is controlled by the gas mixture. This flexibility to deposit films of any B/C ratio is one reason diborane is favored over other less hazardous boron containing gases like deuterated trimethylboron $\left[\left(C_{3}\right)_{3} B\right][7]$ where the gas molecule $B / C$ ratio determines the film $B / C$ ratio.

A glow discharge is used to deposit the film. The glow is maintained in DIII-D using two graphite anodes spaced $180^{\circ}$ toroidally, while the tokamak wall (surface to be covered) is the cathode. The injected gas molecules become ionired (positively charged), accelerate towards the wall and disintegrate upon impact, thereby covering the wall with layers of atoms. Vacuum pumping of byproducts (mainly helium and deuterium from the $0.9 \mathrm{He} / 0.1 \mathrm{~B}_{2} \mathrm{D}_{6}$ mixture) is continuous. Typical DIII-D glow parameters for boronization are 0.006 Torr pressure and $6 \mathrm{~A}$ current at $380 \mathrm{~V}$ dc potential.

Diborane is hazardous requiring special health and safety equipment for handling it. If inhaled, damage to the lungs will likely occur. The short term exposure limit (IDLH) for diborane in air is $40 \mathrm{ppm}$, the continuous exposure limit (TLV) is $0.1 \mathrm{ppm}$. The explosion limits for diborane in air are $0.8 \%$ to $98 \%$ (for comparison, the limits for hydrogen are $4 \%$ to $75 \%$ ). Diborane is a highly reactive chemical agent. Having a $38^{\circ} \mathrm{C}$ auto ignition temperature, it burns upon contact with air. Above approximately $300^{\circ} \mathrm{C}$, diborane dissociates into its elements boron and hydrogen. See Ref. 8 for more detail.

Using diborane in a safe manner is helped by two factors. (1) Sufety and handling equipment is readily available due to the extensive use of the gas by the semiconductor industry. The United States and Pacific Rim region combined use over $550 \mathrm{~kg}$ of diborane each year. (2) If diborane is accidently released to the environment, the water vapor (humicity) in air hydrolyzes it into bydrogen and nearly harmless boric acid $\left[2 \mathrm{~B}(\mathrm{OH})_{3}\right]$ very much faster than air exchanges can dilute the diborane to 0.1 ppm. 
A boronization system was designed for DIII-D to address the hazards of diborane gas discussed in the last section. The system layout (Fig. 1) is like the TEXTOR sysiem layout [4]. Included in the system are the following four passive safety features. (1) Diborane is subatmospheric throughout the entire system except inside the hazardous gas safety cabinet. In the event of a leak in the subatmospheric section, air would enter the system and diborane would not escape into the environment. (2) The diborane used at DIII-D is received from the gas supplier diluted in helium, reducing the chemical potential energy density. (3) The quantity of diborane in a new cylinder is small, less than $125 \mathrm{~g}$, minimizing the environmental hazard in the event of a worst-case accident. (4) The diborane cylinder used by DIII-D has a 0.01 in. orifice included in the cylinder valve for the purpose of restricting the flow out of the high pressure cylinder in the event of a worst-case accident.

The DIII-D boronization system consists of nine subsystems: an outside storage locker, an inside hazardous gas safety cabinet, fixed and portable diborane monitors, coaxial delivery lines, a flow restricting device in the residual gas analyzer (RGA) system, a dedicated vacuum system, thermal and water decomposers, a probe for making film samples, and finally, a safety interlock system. Details of each subsystem are given below.

The diborane cylinder is stored in a locker located outside the building away from normal pedestrian traffic. On the day of boronization, trained personnel wearing self-contained breathing equipment, Nomex jumpouits, and leather gloves move the cylinder to the inside hazardous gas safety cabinet. Immediately after the boronization session, the reverse is done, moving the diborane cylinder back to the outside locker for storage. A roof shades the locker keeping the diborane cool, increasing shelf life. Openings in the locker allow for natural ventilation preventing the accumulation of an explosive mixture if the cylinder leaks. The locker is grounded to earth and is kept locked.

The inside hazardous gas safety cabinet, purchased commercially, hoids one diborane, one helium, and one methane cylinder. The helium cylinder is for purging out the diborane and methane manifolds. A microprocessor (included with the cabinet) cycles the diborane manifold valves inside the cabinet in proper sequence for safe purging and gas delivery. This minimizes the number of times that a person must reach inside the cabinet. Purging of the diborane manifold is aided by a 200 Torr vacuum venturi driven by 100 psig nitrogen. Diborane, and methane flow rates are varied using mass flow controllers located inside the cabinet. A $14,500 \mathrm{l} / \mathrm{min}$ ventilation system is connected to the cabinet exhausting outside the building above the roof and away from personnel. It maintains the cabinet pressure at slightly below atmospheric and continuously draws large quantities of air through the cabinet to dilute a worst-case diborane leak below the explosion limits of diborane and hydrogen. If the ventilation system fails as determined by a delta pressure switch, the safety interlock system stops the diborane flow. Other safety interlccks built into the cabinet that stop the diborane flow are (1) loss of house air for operating pneumatic valves; (2) high diborane delivery pressure due to a regulator failure; (3) power outage; and (4) excess diborane flow due to a line rupture. Also, a water sprinkler head is inside the cabinet for fire suppression.

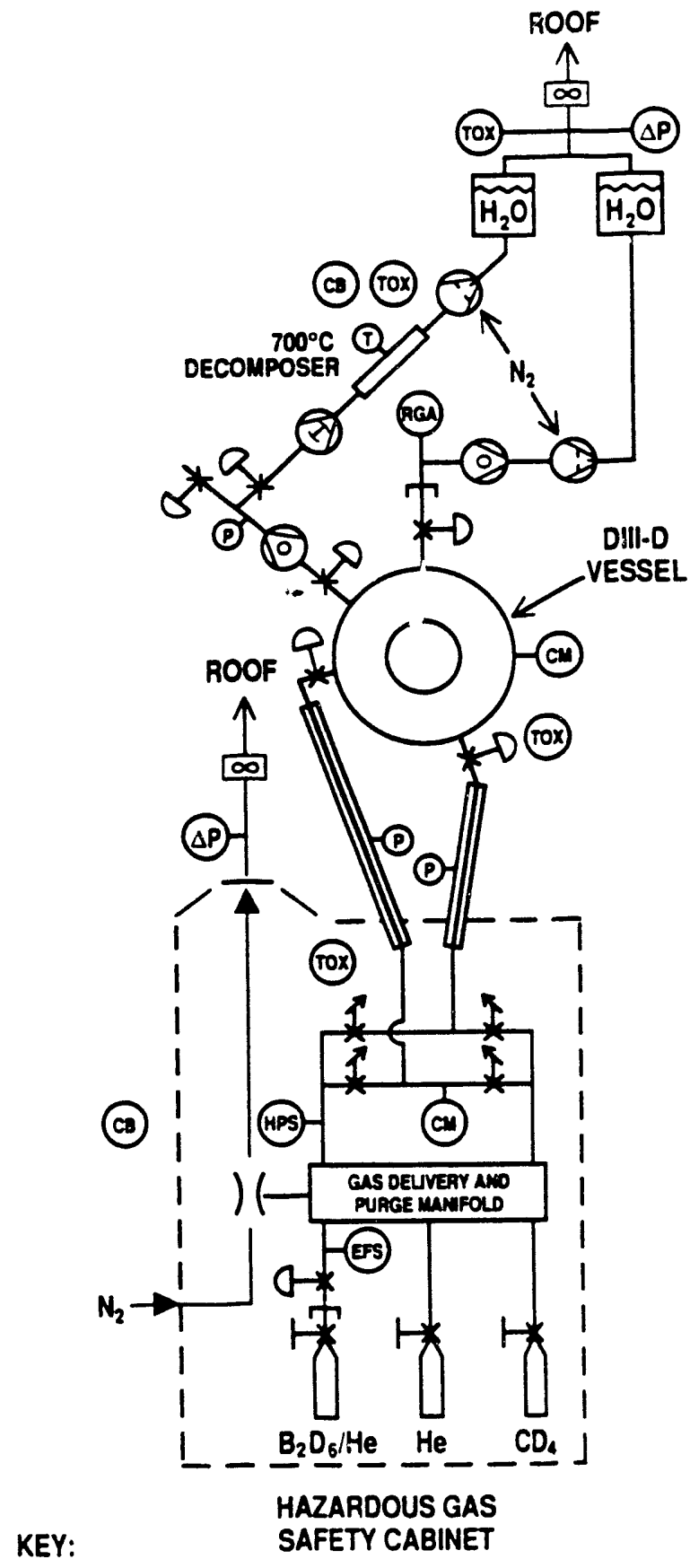

Hx Hand Operated Valve

$0 \times$ Air Operated Valve

rX Flow Controller

it Orifice

(rox) Diborane Monitor Point

(E) Excess Flow Switch

HPS High Pressure Switch

(I) Thermocouple
(D) Pirani Gauge

(C) Crash Button

Ca Capacitance Manometer

) ( Vacuum Venturi

$\infty$ Fan

(2) Turbomolecular Pump

B Rotary Vane Pump

$\Theta$ Roots Blower
FIs. 1. Simplified schematic of DIII-D boronization system. 
The fixed and two portable diborane monitors draw samples to their sensors using internal vacuum pumps. The batterypowered portable monitor is used by personnel during boronization when entering areas that in the event of a failure could contain diborane. The minimum detection time and sensitivity of the portable monitor are $10 \mathrm{sec}$ and $150 \mathrm{ppb}$ diborane in air. The portable monitor is sensitive to other gases (e.g., isopropyl alcohol, hydrogen) resulting in possible false alarms. The fixed diborane monitor sequentially samples for diborane at the following four locations: (1) inside the hazardous gas safety cabinet; (2) at one DIII-D injection point; (3) at the vacuum pumps; and (4) in the vacuum pump exhaust line. The fixed monitor is set to give a warning between 50 and $99 \mathrm{ppb}$. At $100 \mathrm{ppb}$ or more, the diborane flow is stopped by the safety interlock system. The minimum to maximum detection times for $100 \mathrm{ppb}$ or greater are 30 to $180 \mathrm{sec}$. The fixed diborane monitor is not sensitive to other gases or radio frequency.

Two stainless steel coaxial lines (165 and $200 \mathrm{ft}$ long) are used to deliver the boronization gas mixture to DIII-D from the hazardous gas safety cabinet. The inner line is 0.25 in. tubing sealed by welds and leak checked with a helium leak detector. The inside diameter surface is of a microfinish minimizing outgassing. The outer line is 0.5 in. tubing sealed by tube fittings. The space between the two lines is evacuated to less than 1 Torr and closed off creating a jacket vacuum. The jacket vacuum is monitored by a Pirani gauge. If the pressure rises more than 10 Torr during boronization (indicating a leak in either the inner or outer line), the diborane flow is stopped by the safety interlock system. The jacket space can be flushed with nitrogen through valves at each end of the outer line.

Hot filament devices like ion gauges decompose in diborane and are turned off during boronization. Capacitance manometers and Pirani gauges are used for pressure measurements. In the case of the RGA system (a hot filament device), a valve and 0.05 in. orifice arranged in series have been added to restrict inlet flow and increase differential pumping. This limits the total pressure in the RGA to less than $1 \times 10^{-3}$ Torr, allowing its periodic use during boronization to observe cracking patterns. A small $100 \mathrm{l} / \mathrm{sec}$ turbomolecular pump backed by a rotary vane pump provide the differential pumping. Exhaust from the vane pump is treated just like the exhaust from the tolamak vacuum system (i.e., a nitrogen purge, water decomposer, and a dedicated exhaust line).

The tokamak vacuum system uses a normal DIII-D $5000 \mathrm{l} / \mathrm{sec}$ turbomolecular pump. This is backed by a $606 \mathrm{~m}^{3} / \mathrm{hr}$ Roots blower and $65 \mathrm{~m}^{3} / \mathrm{hr}$ rotary vane pump combination used solely for boronizaticu. Both the blower and vane pump use inert perfluoropolyether (PFPE) oil and are designed for corrosive applications and superior leak-tightness. Gate vaives permit switching the turbomolecular pump from the normal DIII-D backing system to the boronization backine system. Between the blower and vane pump is a thermal decomposer, described later. After the vane pump is a water decomposer. A dedicated exhaust line conducts all vacuum pump exhaust out of the building with help from a fan located at the end of the exhaust line on the roof. A nitrogen purge is connected to the vane pump case diluting the boronization byproducts below the explosion limit for deuterium. The purge is not interlocked but the flow and supply are checked before boronization. The purge source is boiloff from a several thousand gallon liquid nitrogen tank which is deemed reliable. The effective pumping speeds of the turbomolecular pump, blower, and vane pump with ther$\mathrm{mal}$ decomposer, are approximately 1500,47 , and $4.6 \mathrm{l} / \mathrm{sec}$, respectively, with a 10.1 Torr-l/sec flow rate into DIII-D of a $0.9 \mathrm{He} / 0.1 \mathrm{~B}_{2} \mathrm{D}_{8}$ mixture. The inlet pressure to the blower is monitored with a Pirani gauge and, if it exceeds 0.6 Torr, the diborane flow is stopped by the safety interlock system.

Thermal and water decomposers are in the system to decompose any unused diborane from either normal or abnorma? operations. The thermal decomposer is a weldment constructed from a 3 in.-diameter stainless steel tube with two internal baffle.s each made from 1/8 lb coarse stainless steel wool. The baffles are captured between screens. A three-zone electric tube furnace provides the heating. If one zone fails, the decomposer remains viable because the three zones are wired in parallel and the two baffles are centered between zones 1 to 2 and 2 to 3 . Temperature is monitored with thermocouples and if it falls below $700^{\circ} \mathrm{C}$, the diborane flow is stopped by the safety interlock system. About 10 in. either side of the furnace, the decomposer tube temperature drops to less than $50^{\circ} \mathrm{C}$, cooled by air. The pressure drop across the decomposer is about 1.4 torr. The two identical water decomposers are made from clear acrylic material and are filled half-full with 0.25 in. glass beads and water. The glass beads break up large gas bubbles ensuring complete hydrolysis of the diborane.

In order to produce film samples, a 20-sample carrier is temporarily attached to the tip of an existing diagnostic probe and inserted inte the tokamak during boronization. Depth profiles of the film samples are made by Auger Electron Spectroscopy and Ar-ion sputtering.

An interlock system has been designed to automatically vent the air pressure to a normally closed pneumatic valve, stopping the flow of diborane gas at the cylinder in the event of a serious malfunction. Additional interlocks not already discussed in this paper include the following: (1) four crash buttons located around the building for use by personnel; (2) high tokamak pressure as determined by a capacitance manometer; and (3) failure of the DIII-D vacuum control computer.

\section{First and Second DIII-D Boronizations}

Two boronization cycles have been completed in DIII-D and each have deposited a film about $100 \mathrm{~nm}$ average thickness. Each used about 1.1 moles of deuterated diborane (no methane) and required five to six hours of glow discharge. The average wall temperature of DIII-D during boronization was $280^{\circ} \mathrm{C}$. Analysis of a film sample showed the film consists of $90 \% \mathrm{~B}$ and $10 \% \mathrm{C}$ (note the analysis was not sensitive to $D$ ). Plasma experiments following boronization were characterized by a ten-to-thirty-fold reduction of metallic impurities and a five-fold reduction in carbon and oxygen impurities as compared to previous experiments [9]. Aftcr boronization, a new regime of very high plasma energy confinement was observed, with energy confinement times a factor of 1.8 above previous DIII-D results [9]. The triple product, $n_{\mathrm{D}}(0) \times \tau_{\text {th }} \times T_{\mathrm{i}}(0)$ was extended from $1.0 \times 10^{20}$ to $2.7 \times 10^{2 n} \mathrm{~m}^{-3} \mathrm{sec} \mathrm{keV}$, a record in DIII-D. $n_{\mathrm{D}}(0)$ is the central deuterium density, $\tau_{t h}$ is the thermal confinement time, and $T_{i}(0)$ is the central ion temperature.

\section{Acknowledgment}

This is a report of work sponsored by the U.S. Department of Energy under Contract No. DE-AC03-89ER51114. 


\section{References}

[1] J. Winter et al., "Boronization in TEXTOR," J. Nucl. Mater. 162-164, 713 (1989).

[2] J. Winter, "A comparison of tokamak operation with metallic getters $(\mathrm{Ti}, \mathrm{Cr}, \mathrm{Be})$ and boronization, ${ }^{n} \mathrm{~J}$. Nucl. Mater. 176177, 14 (1990).

[3] R. Zehringer, H. Künzli, P. Oelhafen, C. Hollenstein, "Oxidation behaviour of boron carbide," J. Nucl. Mater. 176-177, 370 (1990).

[4] H.G. Esser, H.B. Reimer, J. Winter, D. Ringer, "First Boronization of TEXTOR - Concept and Realization," Fusion Technol., 791 (1988).

(5) P.H. La Marche, G.R. Walton, E.D. Perry, D.M. Manos, M. Leonard, G.J. Gettelfinger, H.F. Dylla, H.L. Bush,
"The Diborane Gas Injection and Exhaust System for the Tokamak Fusion Test Reactor," Fusion Technol. (1990).

[6] J. Von Seggern et al., "Properties of a-C/B:H films relevant to plasma-surface interactions," J. Nucl. Mater. 176-177, 357 (1990).

[7] J. Winter, H.G. Esser, H. Reimer, et a., "Borontrimethyl $\mathrm{B}\left(\mathrm{CH}_{3}\right)_{3}$ - A less hazardous substance for boronization," J. Nucl. Mater. 176-177, 486 (1990).

[8] "Diborane Technical Bulletin" (1976); "Diborane Health and Safety Bulletin" (1982); "Diborane Handling Bulletin" (1982). Callery, Pennsylvania: Callery Chemical Co.

[9] G.L. Jackson et al., "A Regime of Very High Confinement in the Boronized DIII-D Tokamak," submitted to Phys. Rev. Lett. (1991). 

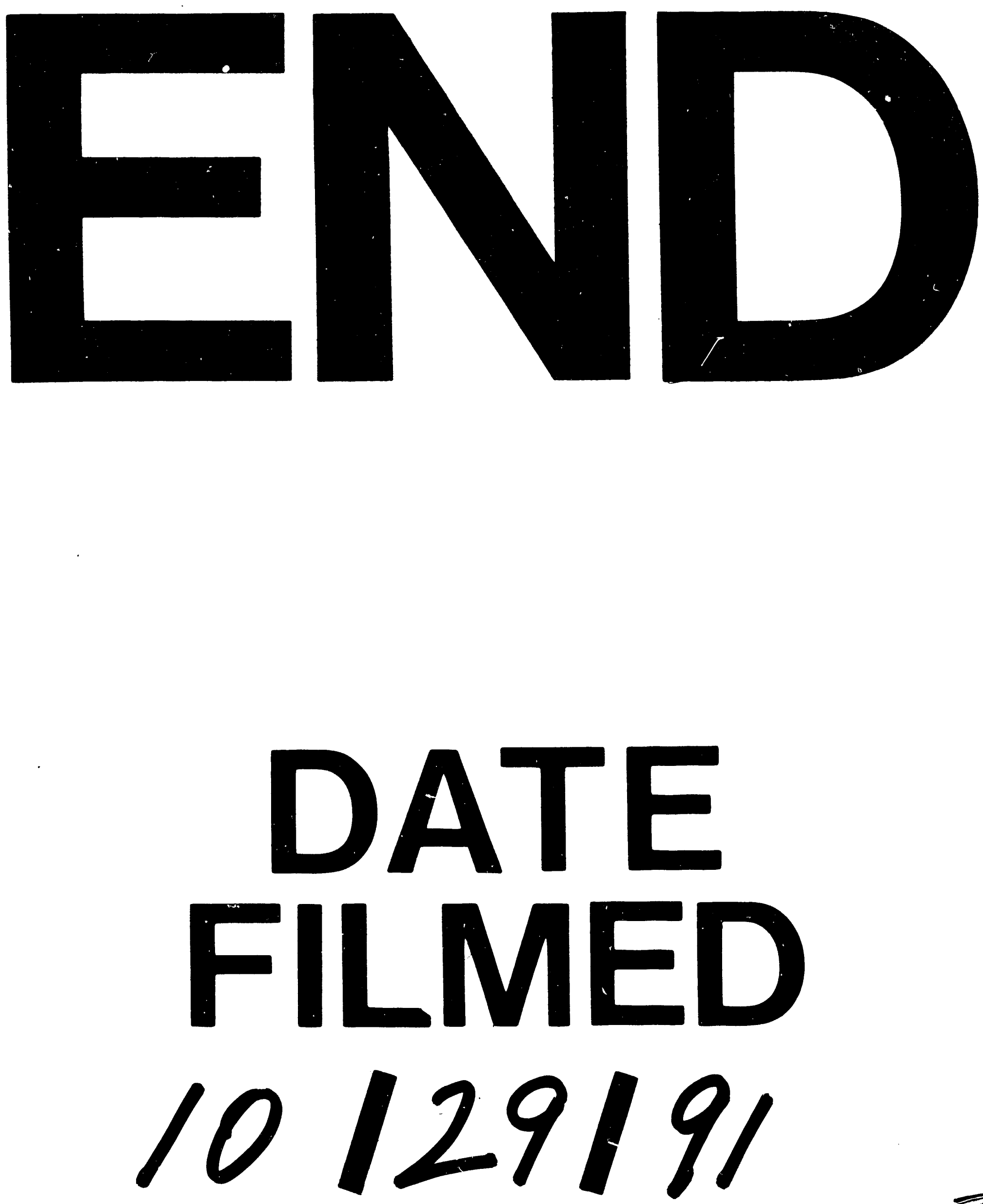
